press release and public statements have contributed to media misinterpretation of what the study does and does not say. "The review does not state the drugs are 'ineffective' or 'useless,'” as was reported in some media stories, he says.

In a joint response to Nature, BMJCochrane said that they felt the press release did "a good job of presenting the main findings". They defend its presentation of the reduction in duration of symptoms as justified, and note that the fuller outcomes were included in the review's summary of its findings. The press coverage, they say, was "not bad in terms of balance and accuracy".

The two organizations agree that the limited statistical power of the trial data on the numbers of hospitalizations and complications makes it difficult to draw reliable conclusions on these. But they argue that their findings of no evidence for any effects challenge past analyses of trials that found that the drugs reduced complications and hospitalizations. They claim that the review did show new findings, for example data on side effects.

RCTs are considered the gold standard for establishing the effectiveness of drugs, and Cochrane restricts itself to meta-analyses of these in its review. But critics note that these small clinical trials were carried out to gain regulatory approval for Tamiflu as treatment and prophylaxis for seasonal flu, which in most cases is mild. This meant that the healthy trial subjects rarely developed complications. In other words, the trials were not designed to test for the severe outcomes that are most relevant to pandemics.

The critics add that observational studies of how large numbers of people respond to treatments under normal medical care can also provide important information on the effectiveness of drugs. In March, for example, an observational study ${ }^{4}$ of 30,000 people hospitalized during the 2009-10 swine-flu pandemic reported that neuraminidase inhibitors reduced mortality by $25 \%$.

But because of its policy of reviewing only RCTs, Cochrane did not include observational data. "Given the limited number of RCTs, and the considerable evidence base on the effectiveness of neuraminidase inhibitors over the past ten years or more, it is difficult to justify exclusion of the observational evidence," says Ben Cowling, a flu epidemiologist at the University of Hong Kong.

$B M J-C o c h r a n e$ said they exclude all observational studies because they are "unreliable for establishing treatment effects".

1. Jefferson, T. et al. Neuraminidase Inhibitors for Preventing and Treating Influenza in Healthy Adults and Children (Review) (Wiley, 2014).

2. Jefferson, T. et al. Br. Med. J. 348, g2545 (2014).

3. Heneghan, C. J. et al. Br. Med. J. 348, g2547 (2014).

4. Muthuri, S. G. Lancet Resp. Med. http://dx.doi. org/10.1016/S2213-2600(14)70041-4 (2014).

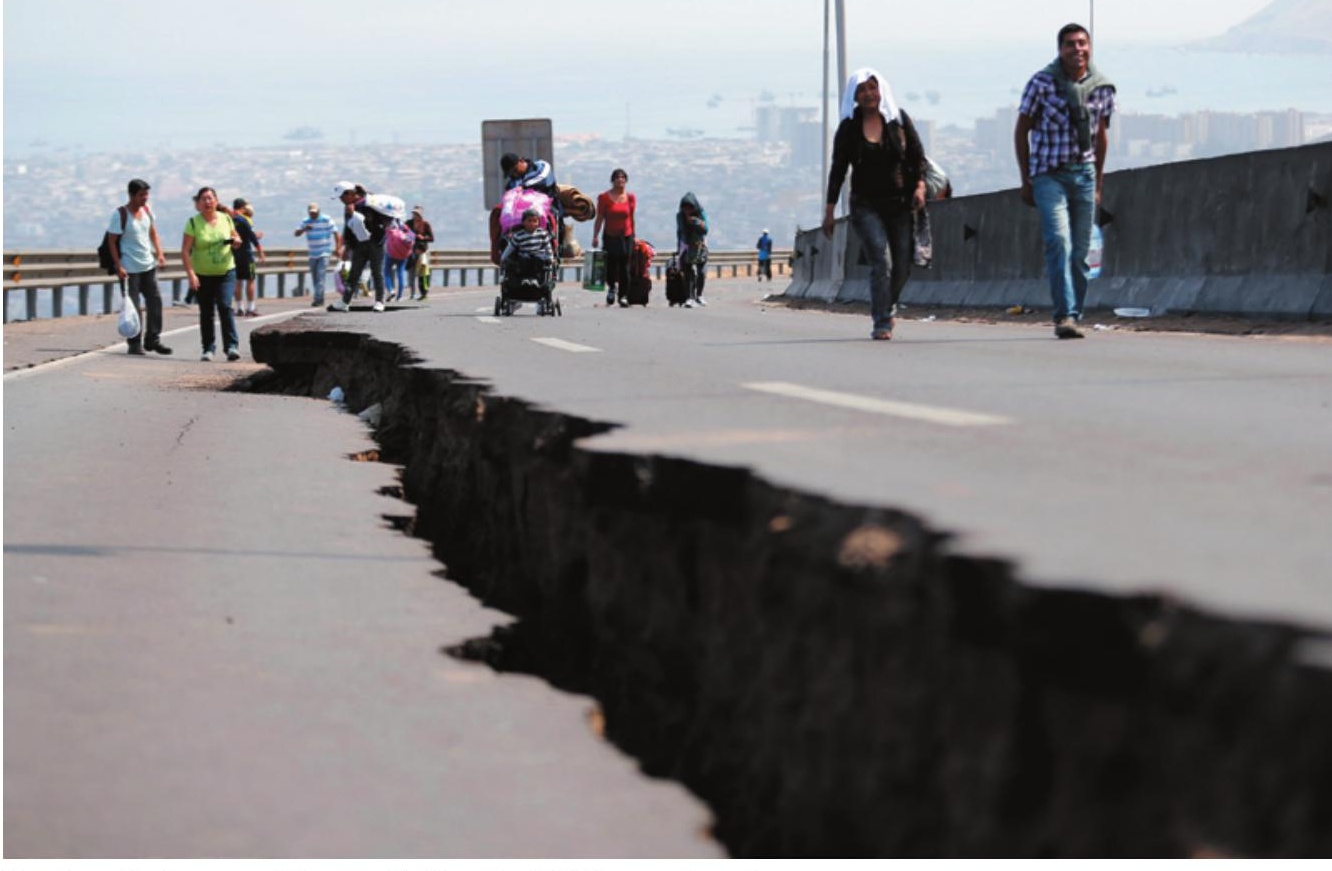

People walk along a road damaged in the 1 April Chilean earthquake.

\title{
SEISMOLOGY
}

\section{Chile quake defies expectations}

\section{Smaller-than-expected tremor has scientists scrambling to redefine rules for areas of extreme seismic stress.}

\section{BY ALEXANDRA WITZE}

$\mathrm{M}$ onika Sobiesiak wasn't expecting the morning of 2 April to start with such an adrenaline jolt. But as she scrolled through a list of earthquakes on her mobile phone, she saw that overnight a series of quakes had rocked the coast of northern Chile - almost exactly where she had installed a seismometer network a few years earlier. "I saw the 8.2," says the geophysicist, who works at the University of Kiel in Germany, "and I rushed to get to my desk."

That 1 April quake, which struck offshore near the village of Pisagua, was the largest in Chile since a magnitude- 8.8 quake hit farther south in 2010. Although the Pisagua quake was not as big and not particularly damaging, it will still go down in the annals of seismology - as an intensively studied earthquake that upends some assumptions about how and when big quakes happen.

In one sense, seismologists knew it was coming. Northern Chile, near the border with Peru, was the only stretch of the country's coastline that had not broken in a large earthquake in the past century (see 'Under pressure'). In 2006, expecting it to go, a GermanFrench-Chilean collaboration blanketed the region with seismometers, tiltmeters and other ground-measuring instruments, creating the Integrated Plate boundary Observatory Chile (IPOC). It captured the Pisagua quake in action, as did Sobiesiak's network.

But the earthquake was not the 'Big One' that seismologists had expected. Only a monstrous earthquake, of around magnitude 9, would have relieved all the geological stress built up in the region. More quakes, on the order of

"A lot of energy
remains to be
released in
north Chile."
magnitude 8 , are still possible, but when they might strike is a mystery. More broadly, the Pisagua event has seismologists rethinking some basic ideas about the risk of earthquakes in similar geological settings elsewhere - places with deep-diving crustal plates, such as Japan and Indonesia.

Over time, earthquakes rupture particular portions of a long fault zone; the unbroken portions are 'seismic gaps' considered ripe for future quakes. Officials in these areas are often told to prepare for the worst-case scenario the biggest possible earthquake in a given seismic gap. But the Pisagua quake shows that this does not always happen, says Susan Beck, a seismologist at the University of Arizona in 
Tucson. Instead, it underscores that seismic gaps can rupture in all sorts of ways, from lots of smaller quakes to just a few big ones.

Chile is an ideal laboratory in which to study such questions because it lies on the margin of a subduction zone, where the Nazca tectonic plate dives - or subducts - beneath the South American plate. Geological stress builds up and then is released in the occasional massive jolt. Chile is home to the largest earthquake ever recorded — one of magnitude 9.5 in 1960 - and accounts for more than one-quarter of the planet's total seismic-energy release.

Pisagua had not seen a major earthquake since 1877, when a tremor of around magnitude 9 ripped through the area. Seismic activity began to pick up last August, when a swarm of small earthquakes struck the area. Another set followed over the new year, and a third cluster occurred in March. These three swarms seem to have prepared the subduction zone to rupture in the big 1 April quake, says Onno Oncken, a geophysicist at the German Research Centre for Geosciences in Potsdam.

Until recently, researchers had thought that the next large earthquake in northern Chile would break the entire interface between the Nazca and South American plates, says Jean-Pierre Vilotte, a seismologist at the Paris Institute of Earth Physics. The Pisagua quake and a magnitude-7.6 aftershock two days later, "are a clear counterexample of this simplistic classification", he says. Together they ruptured just a small portion of the entire region at risk.

Intriguingly, the part of the subduction zone that broke was not the part that had built up the most stress, according to a ground-motion study of northern Chile's seismic gap by Marianne Métois, a geophysicist at the National Institute of Geophysics and Volcanology in Rome, and her colleagues (M. Métois et al. Geophys. J. Int. 194, 1283-1294; 2013). For some reason, the Pisagua quake released stress in areas that were not the most wound up. "A lot of energy remains to be released in north Chile," Métois says.

When the next one comes, seismologists plan to be ready. IPOC has added instruments to capture aftershocks from the 1 April quake and whatever might happen next. Dozens of new seismometers and global-positioning stations have been deployed by teams from Chile, Germany and France, says Sergio Barrientos, director of the National Seismological Centre at the University of Chile in Santiago.

For Sobiesiak, every little bit of data helps. Before the 1 April quake, she thought that the northern Chile seismic gap would rupture either to the north or to the south of the Pisagua area, but not right through it. Now she has some fresh thinking to do. "Each of these efforts really does bring us a step forward," she says.

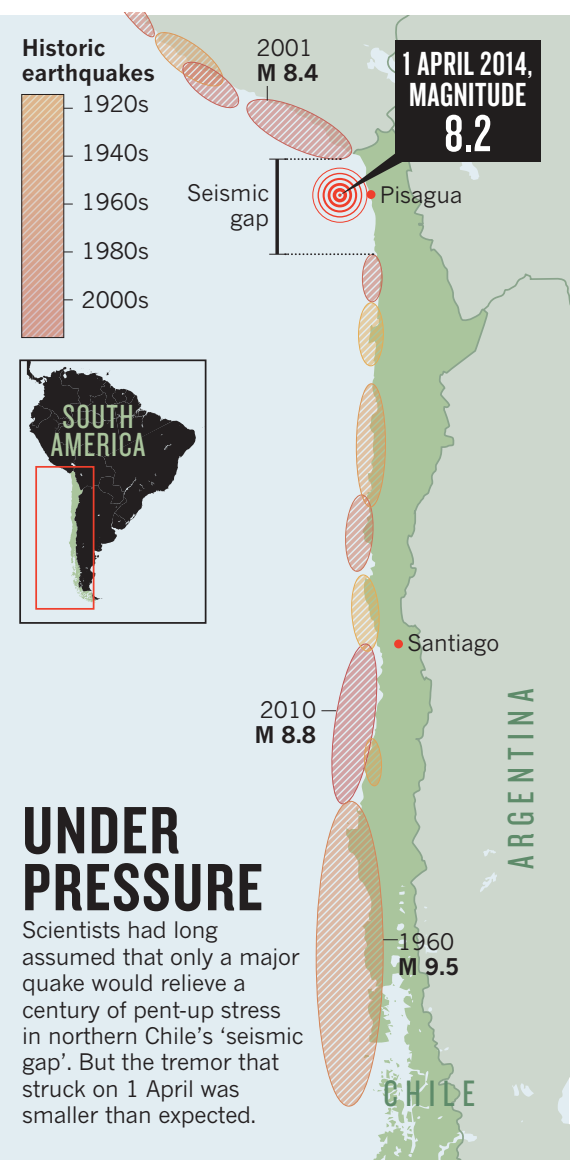

\title{
Quantum communications leap out of the lab
}

\author{
China begins work on super-secure network as 'real-world' trial successfully sends \\ quantum keys and data.
}

\section{BY JANE QIU}

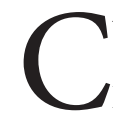
ybersecurity is a step closer to the dream of sending data securely over long distances using quantum physics - spurred by two developments.

This week, China will start installing the world's longest quantum-communications network, which includes a 2,000-kilometre link between Beijing and Shanghai. And a study jointly announced this week by the companies Toshiba, BT and ADVA, with the UK National Physical Laboratory in Teddington, reports "encouraging" results from a network field trial, suggesting that quantum communications could be feasible on existing fibre-optic infrastructure.
Conventional data-encryption systems rely on the exchange of a secret 'key' - in binary 0s and 1s - to encrypt and decrypt information. But the security of such a communication channel can be undermined if a hacker 'eavesdrops' on this key during transmission. Quantum communications use a technology called quantum key distribution (QKD), which harnesses the subatomic properties of photons to "remove this weakest link of the current system", says Grégoire Ribordy, co-founder and chief executive of ID Quantique, a quantum-cryptography company in Geneva, Switzerland.

The method allows a user to send a pulse of photons that are placed in specific quantum states that characterize the cryptographic key. If anyone tries to intercept the key, the act of eavesdropping intrinsically alters its quantum state - alerting users to a security breach. Both the US\$100-million Chinese initiative and the system tested in the latest study use QKD.

The Chinese network "will not only provide the highest level of protection for government and financial data, but provide a test bed for quantum theories and new technologies", says Jian-Wei Pan, a quantum physicist at the University of Science and Technology of China in Hefei, who is leading the Chinese project.

Pan hopes to test such ideas using the network, along with a quantum satellite that his team plans to launch next year (see Nature 492, $22-25 ; 2012)$. Together, he says, the technologies could perform further tests of fundamental 